\title{
TUMBUH KEMBANG ANAK USIA BALITA DI PUSAT PERAWATAN ANAK PUSPA SEHAT UNPAD
}

\author{
${ }^{1}$ Dinny Aprilia, ${ }^{2}$ Wiwi Mardiah, $\&{ }^{3}$ Afif Amir Amrullah \\ ${ }^{1,2,3}$ Fakultas Keperawatan, Universitas Padjadjaran \\ dinnyaprilia95@gmail.com
}

\begin{abstract}
Abstrak
Puspa Sehat UNPAD adalah tempat penitipan anak yang memberikan stimulasi sekaligus deteksi dini gangguan pertumbuhan dan perkembangan. Namun deteksi dini belum dilakukan secara optimal, masih ada anak yang mengalami perkembangan meragukan, kemungkinan ada penyimpangan dan kurang gizi serta pemeriksaan perkembangan yang belum terjadwal. Oleh karena itu perlu diteliti tentang tumbuh kembang balita di Puspa Sehat UNPAD. Metode yang digunakan dalam penelitian ini adalah deskripstif kuantitatif, menggunakan metode teknik total sampling $(n=50)$. Data dikumpulkan meliputi pengukuran berat badan (BB), tinggi badan (TB), dan lingkar kepala serta instrumen kuesioner pra-skrining perkembangan (KPSP) yang dikembangkan oleh Depkes RI. Data dianalisis menggunakan univariat dan disajikan dalam bentuk tabel distribusi frekuensi. Hasil penelitian menunjukkan bahwa proporsi responden yang memiliki pertumbuhan dan perkembangan, hampir seluruh responden termasuk dalam kategori BB/U gizi baik, TB/U normal, lingkar kepala normal dan perkembangan yang sesuai $76,0 \%$. meragukan $12,0 \%$ kemungkinan ada penyimpangan $12,0 \%$. Pemeriksaan tumbuh kembang harus terus dipertahankan dan dilakukan dalam frekuensi yang lebih sering. Saran yang harus dilakukan untuk orangtua harus lebih ditingkatkan stimulasi yang sesuai usia anak, agar anak tumbuh dan berkembang se-optimal mungkin.
\end{abstract}

Kata kunci : Balita, Deteksi dini, Tumbuh kembang

\begin{abstract}
Puspa Sehat UNPAD is a childcare that gives stimulation and early detection of growth and development disorders. But the detection is not optimal yet, there are still kids with dubious growth, possibly irregular and have poor nutritional status and the detection is not scheduled. So it is necessary to research about growth and development of toddlers in Puspa Sehat UNPAD. The method used in this study was descriptive quantitative, total sampling technique used ( $n=50)$. Data collected include body weight, body height, and head circumference also development pre screening questionnaire instrument developed by Indonesian health department. Data analyzed univariate and presented in distribution frequency table. The results indicated that respondents' proportion that has growth and development, almost all are in good nutrition status category, normal heights, normal head circumference and proper development $76,0 \%$, dubious $12,0 \%$ possibly irregular $12,0 \%$. The assessment needs to be maintained and be done more frequently. Advice for parents to stimulate their kids more, so their growth and development can be as optimal as possible.
\end{abstract}

Key words: Early Detection, Growth and Development, Toddler

\section{PENDAHULUAN}

Setiap anak memiliki pola pertumbuhan dan perkembangan yang sama, tetapi kecepatannya lah yang berbeda. Hal ini disebabkan oleh beberapa faktor biologis dan genetik, lingkungan, serta faktor internal dan eksternal. Pengaruh faktor tersebut dapat bersifat sementara ataupun permanen serta dapat mempengaruhi kecepatan dan kualitas kecepatan tumbuh kembang anak. Pengaruhnya dapat memperlambat atau 
meningkatkan kecepatan pada tumbuh kembang anak (Soetjiningsih \& Ranuh, 2013).

Proses deteksi dan stimulasi tumbuh kembang menjadi hal yang tidak boleh dianggap remeh demi terciptanya generasi penerus yang berkualitas serta mampu tumbuh dan berkembang baik secara fisik, sosial, maupun emosional. Stimulasi dini adalah kegiatan merangsang kemampuan dasar anak usia 0-6 tahun agar anak mencapai tumbuh kembang yang optimal sesuai potensi yang dimilikinya. Anak usia 0-6 tahun perlu mendapatkan stimulasi rutin sedini mungkin dan terus-menerus pada setiap kesempatan. Stimulasi yang kurang optimal dapat menyebabkan penyimpangan tumbuh kembang pada anak bahkan dapat menyebabkan gangguan yang menetap. Stimulasi kepada anak hendaknya bervariasi dan ditujukan terhadap kemampuan dasar anak yaitu: kemampuan gerak kasar, kemampuan gerak halus, kemampuan bicara dan bahasa, kemampuan sosialisasi dan kemandirian, kemampuan kognitif, kreatiftas dan moral-spiritual (Awi, 2015).

Penelitian ini dilakukan di Pusat Perawatan Anak Sehat (Puspa Sehat) Universitas Padjadjaran yang pengelolaannya berada dibawah Fakultas Keperawatan Universitas Padjadjaran dengan pelayanan pengasuhan diberikan langsung oleh perawat yang memiliki pengalaman dalam hal perawatan anak sehat maupun sakit dengan memperhatikan proses tumbuh kembang anak dan dibantu oleh tenaga pengasuh non-profesional yang telah memiliki pengalaman dalam hal pengasuhan anak sehat. Serta adanya program pemantauan tumbuh kembang anak dan pelayanan konsultasi menggunakan pendekatan proses keperawatan (pengkajian fisik, bahasa, emosional dan sosial anak, penetapan diagnosa keperawatan, perencanaan asuhan keperawatan serta implementasi asuhan keperawata dan evaluasi asuhan keperawatan).
Hasil studi pendahuluan yang dilakukan di pusat perawatan anak sehat (Puspa Sehat) Universitas Padjadjaran menyatakan bahwa semua anak yang dirawat dan dititipkan di pusat perawatan anak sehat (Puspa Sehat) Universitas Padjadjaran mendapatkan perlakuan yang sama meskipun usia mereka berbeda-beda dan menyatakan bahwa setiap tahunnya jumlah anak yang dititipkan di puspa sehat meningkat karena semakin banyak orang tua yang sibuk bekerja. Fenomena yang terjadi di puspa sehat saat ini adalah, menurut caregiver beberapa anak di puspa sehat cenderung masih ada yang mengalami keterlambatan pada perkembangannya. Contoh, pada anak usia 15 bulan masih ada yang belum bisa mengatakan mama atau papa, masih belum lancar bicaranya, belum bisa jalan sendiri atau jalan dengan berpegangan dan belum bisa berdiri sendiri tanpa berpegangan. Lalu ada juga anak yang mengalami kemungkinan kurang gizi dan caregiver di puspa sehat mencoba menstimulasi dengan memberikan sukro, namun upaya ini mendapatkan persepsi negatif dari orang tua sehingga proses stimulasi gizi oleh caregiver pada anak terganggu (dihentikan

Berdasarkan penjabaran di atas tentunya deteksi dini sangat penting dalam kualitas pertumbuhan dan perkembangan anak terutama balita dan akan berdampak pada status gizi, perkembangan motorik kasar dan motorik halus, perkembangan bahasa/bicara serta perkembangan sosialisasi/kemandirian anak di masa yang akan datang yaitu masa kanak-kanan dan dewasa. Maka peneliti perlu melakukan penelitian untuk mengetahui lebih dalam lagi tentang bagaimana gambaran tumbuh kembang anak usia balita di pusat perawatan anak sehat (Puspa Sehat) Universitas Padjadjaran, serta pemeriksaan perkembangan menggunakan metode skrining yang berbeda yaitu KPSP (kuesioner pra-skrining perkembangan). 


\section{METODE PENELITIAN}

Penelitian dilakukan di Pusat Perawatan Anak Sehat (Puspa Sehat) Universitas Padjadjaran. Waktu pengumpulan data dilakukan pada tanggal 3 Juli - 28 Juli 2017. Rancangan penelitian yang digunakan dalam penelitian ini adalah deskriptif kuantitatif

Populasi dalam penelitian ini adalah seluruh anak usia balita di Pusat Perawatan Anak Sehat (Puspa Sehat) Universitas Padjadjaran terhitung mulai bulan Juli 2017 yang berjumlah 50 anak usia balita. Dalam penelitian ini, pengambilan sampel menggunakan Total Sampling dengan teknik pengambilan sampel secara total. Sampel dalam penelitian ini yaitu anak usia balita di Pusat Perawatan Anak Sehat (Puspa Sehat) Universitas Padjadjaran.

Instrumen yang digunakan berupa kuesioner dan lembar observasi., pada penelitian ini menggunakan instrumen Kuesioner Pra-skrining Perkembangan (KPSP) yang telah dikembangkan oleh Departemen Kesehatan RI pada tahun 2012 (Depkes RI, 2012). Analisis yang digunakan adalah data analisis univariat., yang pertama akan menilai pertumbuhan anak yaitu BB, TB dan lingkar kepala selanjutnya menilai perkembangan anak (ya/tidak), jika responden memilih $Y A=9$ 10 , perkembangan anak sesuai dengan tahapan perkembangan (S). Bila jawaban $Y A=7$ atau 8 , perkembangan anak meragukan (M). Bila jawaban $\mathrm{YA}=6$ atau kurang, kemungkinan ada penyimpangan (P).

Hasil kuesioner dihitung persentasenya menggunakan analisis distribusi frekuensi yaitu analisis yang digunakan untuk mendapatkan gambaran distribusi responden serta untuk mendeskripsikan tumbuh kembang anak usia balita.

\section{HASIL PENELITIAN}

Tabel 1. Distribusi Frekuensi

Karakteristik Responden

\begin{tabular}{llcc}
\hline No & Karakteristik & F & $\begin{array}{c}\text { Persentase } \\
\text { (\%) }\end{array}$ \\
\hline 1. & Umur & & \\
& 0-11 Bulan & 5 & 10,0 \\
& 12-24Bulan & 10 & 20,0 \\
& 25-36 Bulan & 11 & 22,0 \\
& 37-48 Bulan & 12 & 24,0 \\
& 49-60 Bulan & 9 & 18,0 \\
& 61-72 Bulan & 3 & 6,0 \\
\hline 2. Jenis Kelamin & & \\
& Laki-Laki & 34 & 68,0 \\
& Perempuan & 16 & 32,0 \\
\hline 3. & Pekerjaan & & \\
& Orang Tua : & & \\
& Dosen UNPAD & 22 & 44,0 \\
& PNS & 10 & 20,0 \\
& Karyawan/Peg. & 14 & 28,0 \\
& Swasta & 4 & 8,0 \\
\hline & $\quad$ Jumlah & 50 & 100,0
\end{tabular}

Tabel 2. Distribusi Frekuensi pertumbuhan BB/U, TB/U dan Lingkar kepala

\begin{tabular}{|c|c|c|c|}
\hline No & Pertumbuhan & $\mathbf{F}$ & $\begin{array}{c}\text { Persentase } \\
(\%)\end{array}$ \\
\hline \multirow[t]{4}{*}{1.} & $\begin{array}{l}\text { Berat } \\
\text { Badan/Umur } \\
(\mathrm{BB} / \mathrm{U})\end{array}$ & & \\
\hline & $\begin{array}{l}\text { - Gizi } \\
\text { Kurang }\end{array}$ & 2 & 4,0 \\
\hline & - Gizi Baik & 47 & 94,0 \\
\hline & - Gizi Lebih & 1 & 2,0 \\
\hline \multirow[t]{4}{*}{2.} & $\begin{array}{l}\text { Tinggi Badan } \\
(\mathrm{TB} / \mathrm{U})\end{array}$ & & \\
\hline & - Pendek & 3 & 6,0 \\
\hline & - Normal & 46 & 92,0 \\
\hline & - Tinggi & 1 & 2,0 \\
\hline \multirow[t]{4}{*}{3.} & Lingkar & & \\
\hline & Kepala (LK) & 50 & 100,0 \\
\hline & Normal & & \\
\hline & Jumlah & 50 & 100,0 \\
\hline
\end{tabular}

Hasil Penelitian Perkembangan Anak Usia Balita di Pusat Perawatan Anak Sehat (PUSPA SEHAT) Universitas Padjadjaran. 
Tabel 3. Distribusi frekuensi perkembangan Kuesioner Pra-Skrining Perkembangan (KPSP)

\begin{tabular}{lcc}
\hline \multicolumn{1}{c}{ Perkembangan } & F & $\begin{array}{c}\text { Persentase } \\
(\%)\end{array}$ \\
\hline $\begin{array}{l}\text { Perkembangan } \\
\text { Anak Sesuai }\end{array}$ & 38 & 76,0 \\
\hline $\begin{array}{l}\text { Perkembangan } \\
\text { Anak Meragukan }\end{array}$ & 6 & 12,0 \\
\hline $\begin{array}{l}\text { Kemungkinan Ada } \\
\text { Penyimpangan }\end{array}$ & 6 & 12,0 \\
\hline \multicolumn{1}{c}{ Jumlah } & 50 & 100,0 \\
\hline
\end{tabular}

\section{PEMBAHASAN}

Pada hasil penelitian ini didapatkan pertumbuhan anak usia balita di pusat perawatan anak sehat (Puspa Sehat) Universitas Padjadjaran menurut indeks BB/U, TB/U (Kemenkes RI, 2011) dan lingkar kepala yaitu sebanyak $(94,0 \%)$ atau 47 anak memiliki BB/U gizi baik atau normal, lalu $(4,0 \%)$ atau 2 anak memiliki $\mathrm{BB} / \mathrm{U}$ gizi kurang atau kurus dan $(2,0 \%)$ atau 1 anak memiliki BB/U gizi lebih atau gemuk. Untuk TB/U sebanyak (92,0\%) atau 46 anak memiliki TB/U normal, lalu $(6,0 \%)$ atau 3 anak memiliki TB/U pendek dan $(2,0 \%)$ atau 1 anak memiliki TB/U tinggi. Dan untuk lingkar kepala pada anak usia balita di pusat perawatan anak sehat (Puspa Sehat) Universitas Padjadjaran seluruh anak $(100,0 \%)$ atau 50 anak memiliki lingkar kepala normal. Berdasarkan hasil tersebut dapat diketahui bahwa pertumbuhan BB/U, TB/U dan lingkar kepala pada anak usia balita di pusat perawatan anak sehat (Puspa Sehat) Universitas Padjadjaran berada pada kategori BB/U gizi baik atau normal, TB/U normal dan lingkar kepala normal. Hal ini menandakan bahwa anak usia balita di pusat perawatan anak sehat (Puspa Sehat) Universitas Padjadjaran hampir seluruh anak memiliki pertumbuhan gizi yang baik atau normal, tinggi badan normal dan lingkar kepala normal. Gambaran pertumbuhan status gizi yang diperoleh, sesuai dengan yang diungkapkan oleh Almatsier (2010) dimana status gizi pada setiap orang ataupun anak-anak akan berbeda-beda antara satu dengan yang lainnya.

Pertumbuhan merupakan indikator sensitif pada kesehatan anak, status nutrisi dan latar belakang genetiknya. Penyimpangan dari rata-rata tinggi badan, berat badan dan lingkar kepala dapat menunjukkan adanya masalah kesehatan pada anak. Dampak kurang gizi pada anak juga dapat meningkatkan risiko kematian, menghambat perkembangan kognitifnya, dan mempengaruhi status kesehatan pada usia remaja dan dewasa nantinya (Almatzier, Soetardjo \& Soekartri, 2012).

Hal tersebut tidak lepas dari peran aktif orang tua dan pengasuh dalam mengasuh anak usia balita. Pengetahuan orang tua dan pengasuh berhubungan erat dengan status gizi anak, hal ini akan mempengaruhi tingkat pengetahuan yang memadai baik bagi orang tua dan pengasuh yang berusaha untuk mencari informasi melalui media cetak, elektronik, keluarga, kerabat dekat dan tenaga kesehatan lainnya. Orang tua dan pengasuh yang memiliki dan mengasuh anak balita umumnya mampu mengakses pengetahuan tersebut meskipun berada di wilayah terpencil ataupun pedesaan. Sebaliknya, kualitas pengasuh balita yang buruk dan rendahnya pendidikan akan mempengaruhi kualitas dan kuantitas asupan makanan yang menyebabkan balita tersebut mengalami gizi buruk atau sangat kurus (Depkes, 2005).

Pada hasil penelitian yang didapatkan perkembangan anak usia balita di pusat perawatan anak sehat (Puspa Sehat) Universitas Padjadjaran yaitu sebanyak $(78,0 \%)$ atau 39 anak usia balita memiliki perkembangan anak sesuai, lalu (12,0\%) atau 6 anak usia balita memiliki perkembangan anak meragukan dan $(12,0 \%)$ atau 6 anak usia balita memiliki perkembangan kemungkinan ada penyimpangan. $\mathrm{Hal}$ ini menandakan bahwa sebagian besar perkembangan anak memiliki perkembangan anak sesuai, namun untuk hasil perkembangan anak 
meragukan dan kemungkinan ada penyimpangan memiliki presentase hasil yang sama yaitu $(12,0 \%)$ sebanyak 6 anak perkembangan meragukan dan (12,0\%) sebanyak 6 anak kemungkinan ada penyimpangan. Pada hasil tersebut dapat dikatakan bahwa di pusat perawatan anak sehat (Puspa Sehat) Universitas Padjadjaran menunjukkan bahwa sebagian besar dari responden adalah perkembangan anak sesuai, sedangkan kemungkinan ada penyimpangan dan perkembangan meragukan sama-sama berjumlah 6 anak.

Penelitian yang dilakukan Riska (2016), didapatkan hasil dari 184 responden, sebagian besar perkembangan sosial anak usia 1-3 tahun yang diasuh orang tua dalam kategori sesuai yaitu 57 responden (62\%). Hasil penelitian ini mengindikasikan bahwa anak usia 1-3 tahun yang diasuh orang tua belum mencapai kematangan sosial yang artinya anak belum dapat menyelesaikan tugastugas yang terdapat dalam setiap aspek kematangan sosial sesuai dengan usia fisiknya dan sebagian besar perkembangan sosial anak usia 1-3 tahun yang diasuh TPA dalam kategori di atas rata-rata yaitu 80 responden $(87 \%)$ Hasil penelitian ini mengindikasikan bahwa anak usia 1-3 tahun yang diasuh TPA sudah mencapai kematangan sosial yang artinya anak sudah dapat menyelesaikan tugastugas yang terdapat dalam setiap aspek kematangan sosial di atas rata-rata usia fisiknya.

\section{SARAN}

Berdasarkan hasil-hasil penelitian yang telah disimpulkan di atas, maka dapat diajukan beberapa saran, sebagai berikut:

Pengelola Pusat Perawatan Anak Sehat (Puspa Sehat) Universitas Padjadjaran sebaiknya melakukan pengawasan dan evaluasi berkala mengenai kinerja caregiver Puspa Sehat agar caregiver Puspa Sehat termotivasi untuk menjalankan tugas dan fungsinya secara lebih optimal.

Pihak Puspa Sehat lebih meningkatkan kualitas Puspa Sehat secara keseluruhan, misalnya dengan menambah jumlah dan jenis alat permainan edukatif yang dapat membantu menstimulasi perkembangan anak, meningkatkan jumlah dan kualitas caregiver Puspa Sehat serta meningkatkan kualitas makanan yang diberikan kepada anak untuk pertumbuhannya.

Bagi Pengasuh Puspa Sehat dan Orang Tua diharapkan agar lebih meningkatkan kualitas pengasuhan dan memberikan stimulasi tumbuh kembang pada anak serta melakukan pengukuran tumbuh kembang anak secara berkala guna mendeteksi diniagar anak dapat tumbuh kembang dengan se-optimal mungkin dan mencapai proses tumbuh kembang yang sesuai dengan usianya.

\section{DAFTAR PUSTAKA}

Adriana, D., (2011). Tumbuh Kembang \& Terapi Bermain pada Anak. Jakarta: Salemba Medika.

Akbar, R., \& Hawadi., (2001). Psikologi perkembangan anak - mengenal safat, bakat dan kemampuan anak. PT Gramedia Widiasarana Indonesia: Jakarta.

Almatsier, S., (2010). Prinsip Dasar IImu Gizi. Jakarta: PT Gramedia Pustaka Utama.

Almatsier, S., \& Soetardjo, S., \& Soekarti, M., (2011). Gizi Seimbang Dalam Daur Kehidupan. Jakarta: PT Gramedia Pustaka Utama.

Departemen Sosial RI., (1995). Pedoman Perlindungan Anak. Jakarta: Direktorat Kesejahteraan Anak, Keluarga dan Lanjut Usia \& Direktorat Jenderal Bina Kesejahteraan Sosial Departemen Sosial RI. Retrieved September 2017

Depkes RI,. (2005). Rencana Strategi Departemen Kesehatan. Jakarta: Depkes RI. 
(2006). Profil Kesehatan

2005. Jakarta.

, (2012). Pedoman

pelaksanaan stimulasi, deteksi dan intervensi dini tumbuh kembang anak tingkat pelayanan kesehatan dasar. Jakarta: Depkes RI.

Fauzi S.O.H., (2015). Perbedaan Tumbuh Kembang AnaK Toddler Yang Diasuh
Orang Tua Dengan Yang Dititipkan Ditempat Peneitipan Anak (TPA), $1123-1130$.

Febri, A.B., \& Marendra Z., (2008). Buku Pintar Menu Bayi. Jakarta Selatan: PT Wahyu Media. Cetakan II.

Fida, M., (2012). Pengantar IImu Kesehatan Anak. Jogjakarta: D. Medika 